\title{
Comparison and Analysis of a Building with 4D Modeling
}

\author{
Nehad ali khan, Niyaz ahmed shareef, Syed mohd hyder moosvi, Syed nemath \\ uddin, Yhsanullah khan \\ (Department of Civil engineering, lords institute of engineering and technology, India) \\ (Department of Civil engineering, lords institute of engineering and technology, India) \\ (Department of Civil engineering lords institute of engineering and technology, India) \\ (Department of Civil engineering lords institute of engineering and technology, India) \\ (Department of Civil engineering, lords institute of engineering and technology, India)
}

\begin{abstract}
Planning of projects in construction industry is assuming a critical part inside the advancement of development industry. In any case, illustrating a fitting development arrange constitutes a standout among the most convoluted difficulties for development extend group. An extensive variety of arranging procedures have been examined and actualized however they are not sufficiently qualified to fulfill the craving of development gatherings and enhance the development execution. There is as yet a gigantic uniqueness among execution and arrange. In this manner, a proficient and viable arranging technique is seriously expected to improve the venture execution and to limit the danger of cost invading and postponements. This proposal plans to concentrate distinctive parts of $4 D$ modeling and to discover its effect on the development arranging procedure, and how to profit most from this innovation. A careful writing audit was directed and distinctive contextual investigations were dissected to decide the advantages and constraints of $4 D$ modeling on the development in construction industry. The review finished up $4 D$ modeling as a promising device for construction industry. The most huge advantages of $4 D$ modeling decided are better perception of development work, better correspondence among venture groups and expanded arranging productivity.
\end{abstract}

Keywords: 4D modeling, development, construction, planning, , project

\section{Introduction}

For individual parts with basic geometries 2D CAD will permit drawings to be made quicker, however the yield might be only an arrangement of 2D drawings. These are not perfect for speaking to an intricate item, particularly when speaking with your plan group, clients, salesmen, purchasers, and providers, since they are liable to distortion and mistake, which thus can turn out to be exorbitant and tedious for an organization. 3D is the way we actually picture questions in our reality, in this manner joining more than one perspective of a $2 \mathrm{D}$ specialized drawing is not basic practice for everybody. Since the last decade popularity of 4D modeling has been gradually increased and taking the market to higher level . This $4 \mathrm{~d}$ modeling is combining time with 3D models. Many great projects have been made by using 4D modeling. Some of the projects made with 4D modeling are London's Heathrow airport (England) Disney land in Hong Kong, pilestredet park in Oslo Norway, giant pelletizing plant in Sweden. Planning of the construction projects is highly difficult job for contractor. The contractor has to select most easy construction method for the different types of task in a project and also the to provide resources in such a way that the resources reduction is less, thus minimizing the time of project thus by using 4D modeling a contractor can achieve major benefits for a project .A $4 \mathrm{~d}$ model associate part of 3D modeling with the schedule of the project. This allows owners to view the project before the construction of the project. Mostly students in civil engineering learn to analyze design of the projects and plan the construction of project by reviewing the drawings on the paper or $2 \mathrm{D}$ drawings and by using CPM (critical path method ) schedule. By combining 3D models with 4D models it becomes one visualization and it provides disclosure to the owners, stake holders of the project. By using 4D model we can detect the problems faced in scheduling of the project. It also helps in reducing the conflicts on the construction site, high labor wages, insufficient material on site. By using 4D models we can save lot of money. One of the key benefits we can gain from 4D modeling is scheduling and visualization of construction before the project is made. Thus visualization of project improves the communication and coordination between owners and contractors. The relevance of price is very high in construction industry where the success of the project is highly dependent on planning of the project. With the help of $4 \mathrm{~d}$ model $15 \%$ of problems in project can be classified before the beginning of the project. Scheduling of project is one of the most important part of the project for all parties involved in the project. it defines CPM ( critical path method) by scheduling of project using $4 \mathrm{~d}$ modeling we can achieve , detailed estimation of the project, allocation of the resources and demand of the resources, flow of the cash smoothly. 4d model provides frame work for the project. With WBS( work break down structure) the project can be divided into super structure and sub structure with this we can go detailed into the project. 


\subsection{Statement of problem}

Planning and scheduling is one of the most basic and important part of any construction project. The interpretation of a plan to a development plan includes a few stages of human understanding and requires control of information learning in the organizer's brain. The current arranging procedure is to a great extent manual and time-consuming handle. Current practices of development venture arranging include various approach/methods that demonstrate conditions and sequencing of venture exercises. A portion of the systems are bar outlines, CPM based system graphs, and time-changes chart. None of these systems have the ability of displaying and imagining both the sequencing an execution example of exercises. Customary advance following methods are work concentrated, at times subject to transaction, and regularly determined by hidden rule. The development business has issues. As said before the work procedure with $2 \mathrm{D}$ drawings is not productive and inclined to mistakes and can cause problems to designers and this may lead to conflicts on site or poor construction management on site. Sometimes these may lead to costly mistakes and cause damage to contractors

\subsection{Objectives of Research}

Research Aim:

The Aim of the research is to compare and analyze a building with 4D modeling.

Research objectives:

- To survey how visit each of these causes happen.

- Conduct a review of past and current practices in projects

- Explain how the execution of 4D modeling has been done and to what degree.

- Clarify what lessons can be gained from the execution procedure up until this point

- To survey how serious the effect of these causes will be on the aggregate cost of the extend

\section{Literature review}

Progressively, development arranging is assuming an imperative part inside the improvement of development industry (Allen and Smallwood, 2008). It includes following once more from the outcome and recognizing the successions of occasions which prompt that outcome. This is a testing work for the organizer since the ultimate results of development ventures are impractical to see until they are finished (Hendrickson, 2000). Besides, the unavoidable way of vulnerabilities and intricacy of development ventures are additionally assembled to make more mind boggling challenges for venture group in achieve development arranging (Li, Chan, Huang, Guo, Lu, and Skitmore, 2009). Zanen and Hartmann (2010) called attention to that it is imperative to adequately prepare in the early phase of a venture; to indicate potential blunders, get ready conceivable arrangements and to dole out work errands to the perfect individuals with the correct methods. Those are what will improve the rate of accomplishment. In any case, development arranging is not a procedure just restricted in the period before development's genuine begins; it ought to be impressively considered amid the venture life cycle and would require re-arranging if something incorrectly ought to happen (Hendrickson, 2000). Not exclusively can a powerful and legitimate arrangement restrain the likelihood of issues event, it additionally reduce the unfavorable results of such issues (Zanen and Hartmann, 2010). The point of arranging is to create required exercises and in addition their reliance also, accordingly guaranteeing that the venture will be finished inside the best conduct of financial aspects, security and ecological acknowledgment (Zanen and Hartmann, 2010). In a general sense, development arranging partners with the recognizable proof of basic exercises that lead ventures to their ultimate results. Organizers need to completely investigate the successions, the usage and furthermore effects of such different exercises. Thereafter, in view of the assessment and encounters from past tasks, choices will be made to figure out what methodologies and execution techniques are the most advantageous. At the end of the day, through development arranging, reasonable advancements are chosen; work errands are allotted assets are dispensed and extend members as well as the connection between them are distinguished (Hendrickson, 2000).

\section{Methodology}

\subsection{Introduction}

Choosing a fitting examination technique that best answers the exploration question is fundamental to the solidness and legitimacy of the examination. It is basic to state how the exploration plans to accomplish its destinations. In this area, the examination talks about how it means to accomplish its points and goals, and will start with an outline of the chose explore rationality, trailed by the procedure and the structure for this examine. The examination reasoning will be trailed by a talk about the examine approach utilized. The discourse about 
the exploration technique incorporates an outline of quantitative and subjective research strategies, and choice criteria, and the examination technique. An itemized avocation of the information gathering technique will be given by taking a gander at access to the field and meeting plan, talk with style and questions, moral contemplations and determination of the organizations, trailed by a depiction of the information investigation technique utilized

\subsection{Stance of this study}

Inside the setting of the examination theory, the point of this exploration is the improvement of a system for the reception of 4D modeling by the construction industry. The ontological position of this examination falls into the subjectivism continuum as this procedure includes diverse partners and the reality that their "subjective" recognitions and choices by and large, and "socially develop" what is viewed as the 4D modeling "wonders". Furthermore, this examination incorporates extraordinary accentuation on the selection of 4D modeling by the development business observations and encounters of different development organizations who have as of now embraced IT in their procedures will be broke down. As needs be, this exploration perceives furthermore, values such contrasts and has subsequently used top to bottom meetings with a number of development organizations and specialists to comprehend their distinctive observations. Starting there of view, the epistemological position of this examination will lie in the interpretive approach. Moreover, the information gathering process incorporates interviews with various sources.

\subsection{Inductive Approach}

The standard goals of this examination are to comprehend the purposes for the moderate pace joining of cutting edge IT, for example, 4D modeling by the construction industry. The examine included in this review is deductive approach

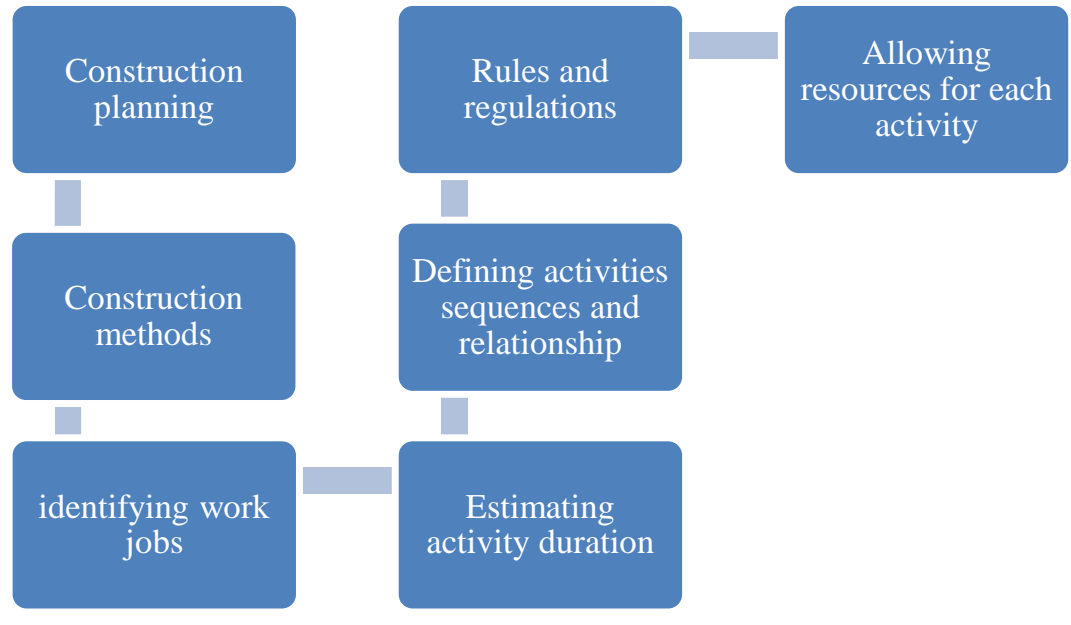

(Fig-1) representing construction process

\section{DATA ANALYSIS}

This section covers the examination of the contextual analyses and writing survey alongside reflections and examination about research questions. After the collection of data, data analysis was commenced. Analysis of data was processed in the following method.

- Rectification of data which is collected.

- Application of the rectified data.

- Processing of the data.

- Using the processed data for the conclusion.

During the analysis process the results were drawn as the advancement in the construction industry by using the 4D modeling as a key tool to startup a project.

While starting a project it's necessary to know the profound value and also the time it could be complete. It was clear during the process that usage of $4 \mathrm{D}$ modeling not only helps in a better visualization of the project but also the improved management of the project throughout its life. 
By analyzing it was clear that modeling of a project by using rivet as a modeling tool and primavera as project managing tool has great amount of advantages over AutoCAD 3D and the manual project managing methods. The following are the advantages noticed during the analysis process:

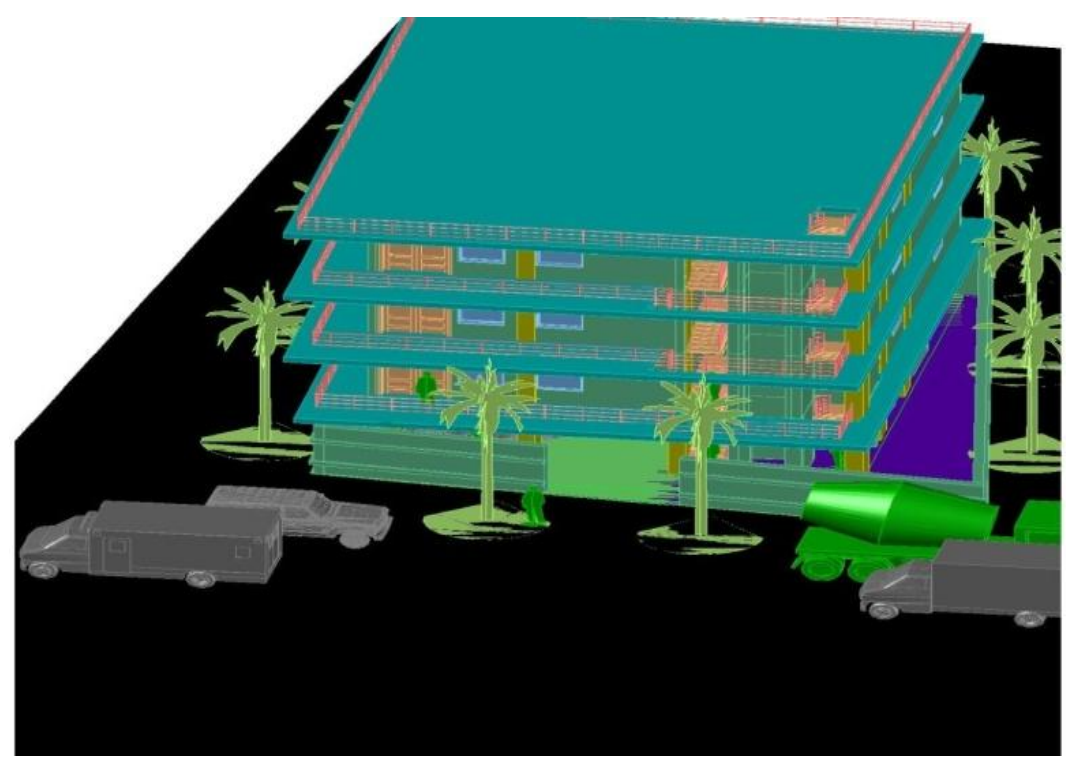

(Fig-2) The exterior of the building prepared using AutoCAD

Designers and architects frequently depend on drawings and models of their activities to help in their work. Notwithstanding, 2D PC helped plan (CAD) models don't generally furnish these experts with the speed and precision they have to finish undertakings or discover answers for difficulties. 3D demonstrating has been utilized by draftsmen around the globe for a long time to enhance the productivity and stylish of their plans

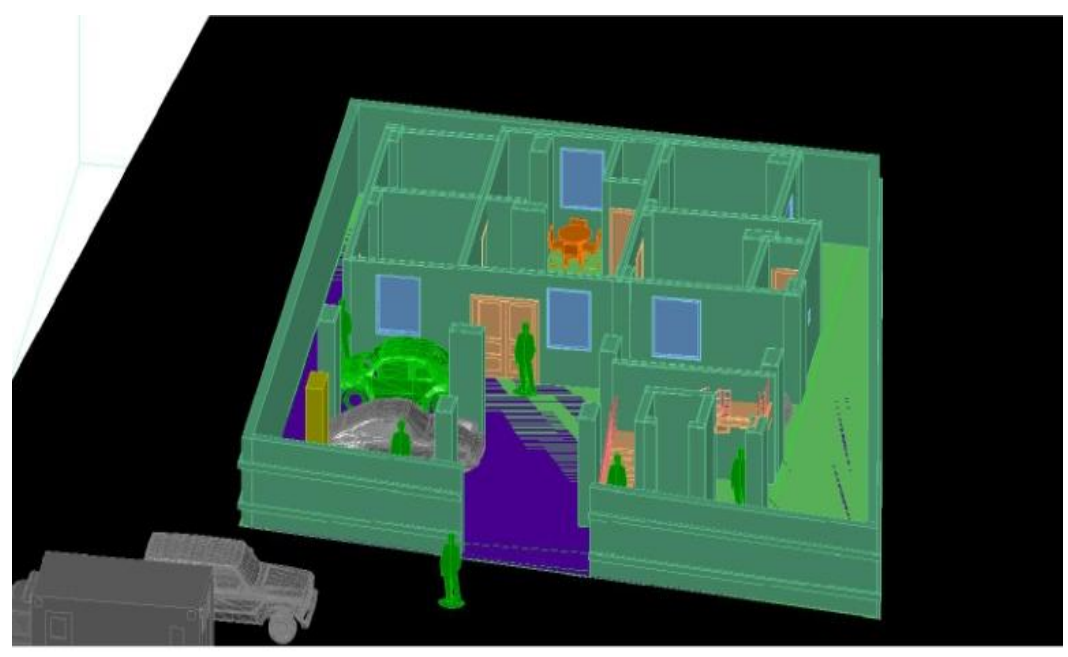

(Fig-3) The floor plan of the building by AutoCAD 3D

The general 3D plan made in AutoCAD 3D which not much highlighted work and visual effects though AutoCAD 3D have been widely used but why to stick with the old techniques when we have a much effective and advance software available in the market. Notwithstanding all the visual advantages AutoCAD common $3 \mathrm{~d}$ gives an assortment of in-assembled documentation reports that stores information utilized, in light of various levels of the creation procedure. This viewpoint gives organizations and specialists, top to bottom, instructive and astute reports that are profoundly required in the usage and arranging phase of the physical development. Arrange, envision, alter and execute your thoughts, and carry it into physical reality with this stunning structural designing project 


\subsection{Designing of buildings in Revit}

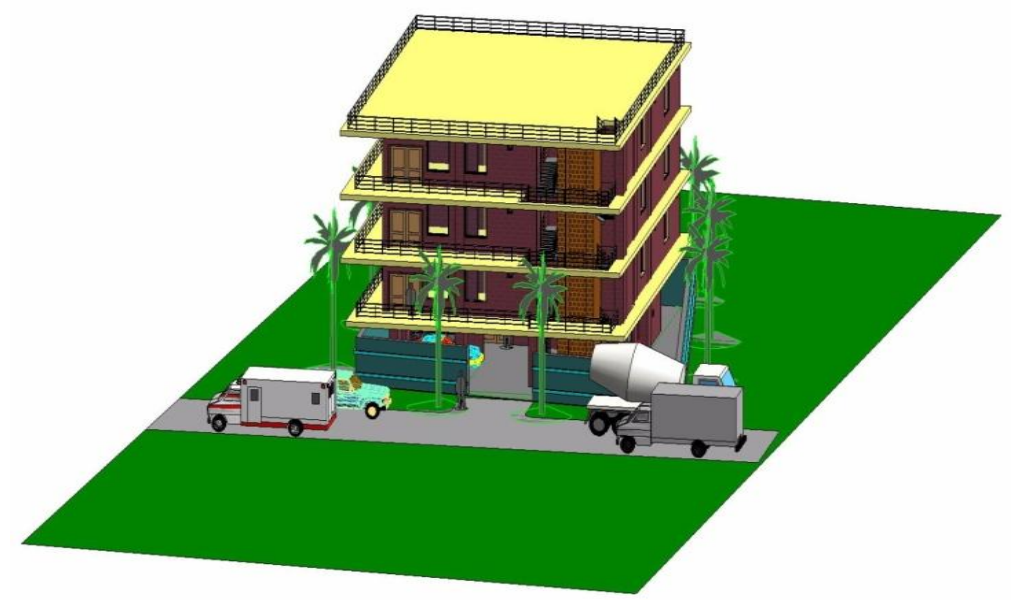

(Fig-4 ) The exterior model of the same building by Revit

Revit has changed the engineering configuration, drafting and demonstrating forms by achieving considerable upgrades in exactness and proficiency. With Revit programming, engineering originators can now quickly portray out unpleasant formats of a story plan, or roll out improvements to the standard arrangement of building outlines and right away let their clients review their future homes

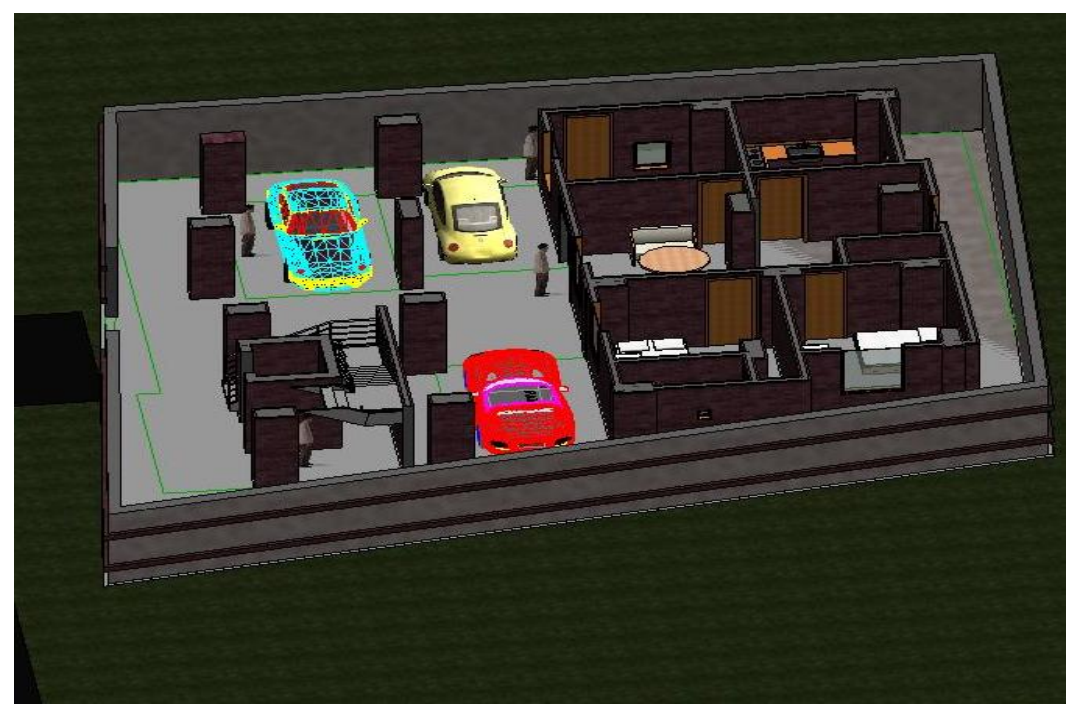

Fig-5 Floor plan of the building using Revit

With Revit programming, engineering planning and drafting turns out to be quick and precise. In Revit design demonstrates, all building parts, for example, arrangements, areas, and rises are wisely associated with each another. At whatever point a change is made to the model, the product consequently refreshes each related segment, influencing the entire building model. By using Revit software, architectural designers can quickly sketch a rough layout of the floor plan, or make changes to the standard set of building designs and instantly let their customers preview their future homes. 3D design views give designers to try out different design ideas and guide their design decisions at early stage. With the help of Revit we were easily able to make a floor plan of a $\mathrm{G}+3$ building. As shown in the figure above we were able to show all the details of the ground floor of a building accurately by using this we can easily be able to detect the mistakes or any other problems in the project even if it before constructed 


\section{TABLE}

\begin{tabular}{|c|c|c|}
\hline Basis & AutoCAD & Revit \\
\hline Definition & $\begin{array}{l}\text { AutoCAD is a 2-D 3-D computer } \\
\text { aided software application used in } \\
\text { architecture, construction to assist } \\
\text { in preparation of construction and } \\
\text { other engineering plans }\end{array}$ & $\begin{array}{l}\text { Autodesk Revit is (BIM) product permitting } \\
\text { users to design a building, structure and its } \\
\text { elements in 3D, the way to annotate the model } \\
\text { with 2D drafting elements and access building } \\
\text { information from the building models } \\
\text { information. }\end{array}$ \\
\hline usability & $\begin{array}{l}\text { With AutoCAD you're working } \\
\text { with lines to make basic geometry } \\
\text { which represents real life objects }\end{array}$ & $\begin{array}{l}\text { With revit you're working with real life } \\
\text { information. furthermore with revit we are } \\
\text { operating in one view like a floor plan, alternate } \\
\text { views are also being generated }\end{array}$ \\
\hline suitability & $\begin{array}{l}\text { AutoCAD is considered best for } \\
2 \mathrm{D} \text { drawings i.e. where precise } \\
\text { line of work is needed }\end{array}$ & $\begin{array}{l}\text { Revit is considered best for modeling, } \\
\text { generating cost schedules, collaboration and } \\
\text { change management }\end{array}$ \\
\hline industry & $\begin{array}{l}\text { AutoCAD is employed across a } \\
\text { large range of industries, by } \\
\text { architects, project managers, } \\
\text { engineers, designers, and different } \\
\text { professionals }\end{array}$ & $\begin{array}{l}\text { Revit software is mainly designed for, structural } \\
\text { engineers, architects, designers, MEP engineers, } \\
\text { and contractors. }\end{array}$ \\
\hline flexibility & $\begin{array}{l}\text { When compared to revit, } \\
\text { AutoCAD is less flexible }\end{array}$ & $\begin{array}{l}\text { Revit is more flexible, it enables you to do } \\
\text { coordination of the job faster }\end{array}$ \\
\hline
\end{tabular}

Usage of revit has gradually increased over the last decade with AutoCAD you're using lines to create basic geometry that represents real life objects. With Revit you're using geometry that's equipped with real life information. In addition to that, with Revit while you're working in one view like a floor plan, other views are automatically being generated as well, like an elevation for example.

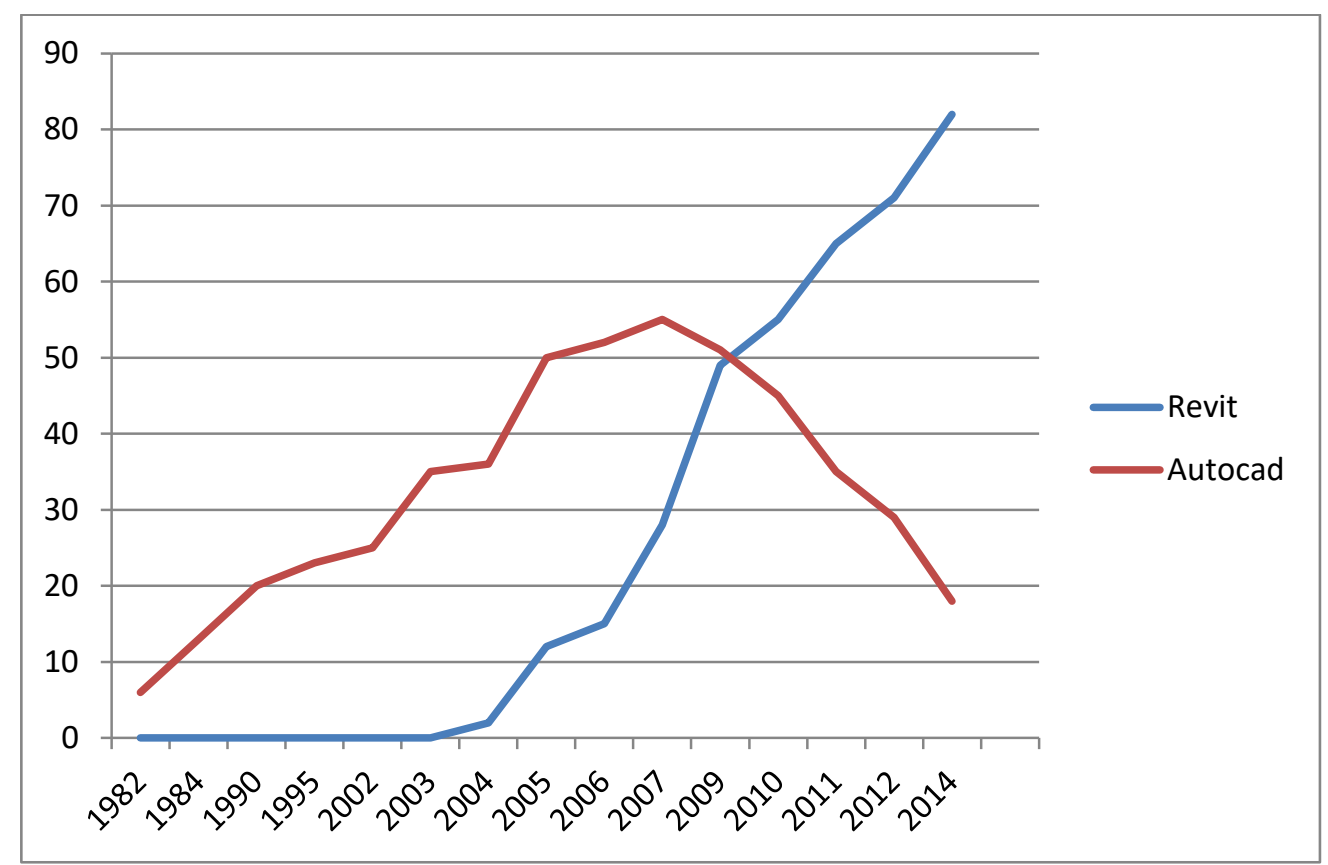

Fig-6 shows the usage of Revit and AutoCAD over the last decades 


\subsection{Critical path method (CPM)}

Critical path method (CPM) has been used for planning and scheduling in Primavera Scheduling of activities is possible. The CPM identifies the entire chain of activities. Often, during the initials stages of the project the number of activities and the cost requirements might be high; but as the project progresses the activities might sort themselves out into routine or critical. Project managers, instead of tacking the entire issue, can focus their attention to groups of activities that are immediate and have the ability to impact the next downstream activity. By using CPM in primavera we were able to identify slack and float time in the project. Thus we were able to identify when resources that can be reallocated to different activities and the shifting and moving of activities to best optimize the utilization of the resources

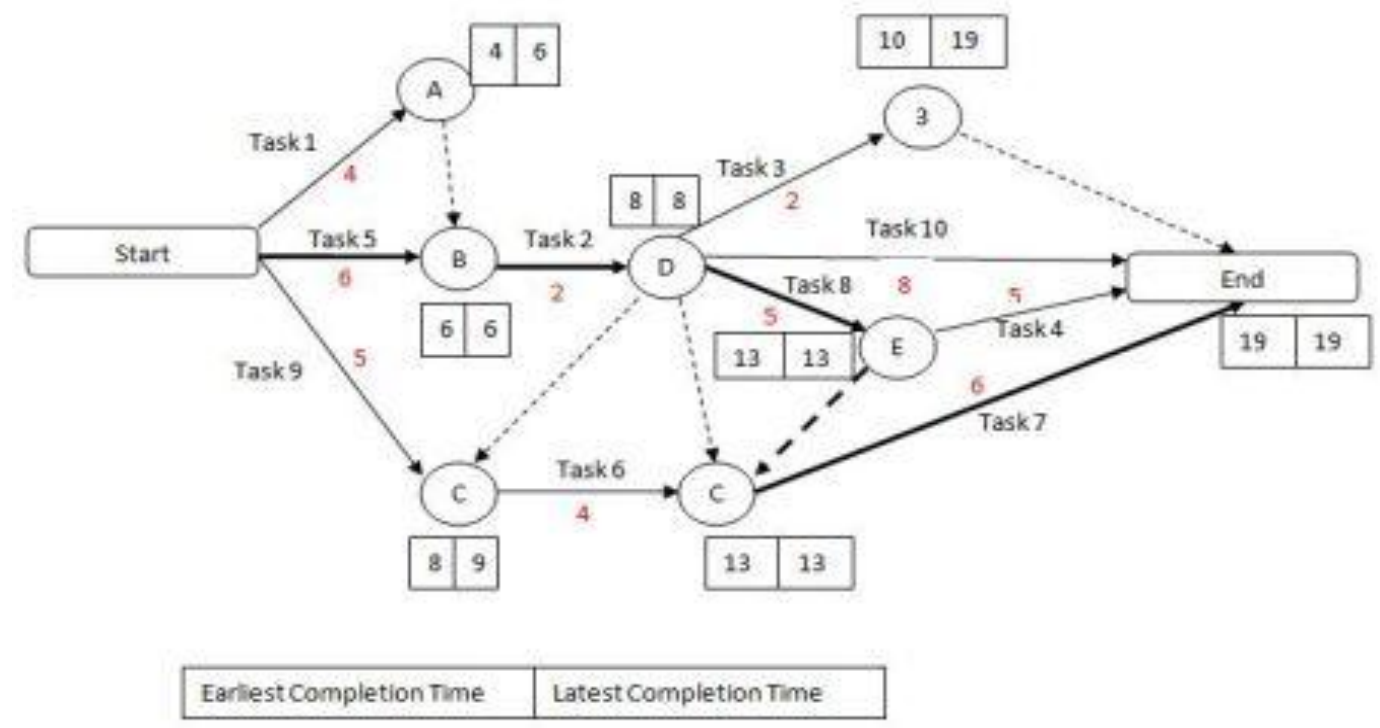

\subsection{Primavera in 4D modeling}

Fig-7 shows critical path method

Primavera can make a set of tools compromising of all the activities done in a project such as activities, WBS (work break down structure), reports, resources, cost reports, cost accounts and all the activities in a project

Primavera is wonderful apparatus of venture administration programming. It helps you to arrange, direct, watch and track the result of your organization. It is utilized as a part of all segments, for example, IT, Mechanical, Civil, or any kind of activities. Primavera is bound for you by arranging architects, organizers, and schedulers

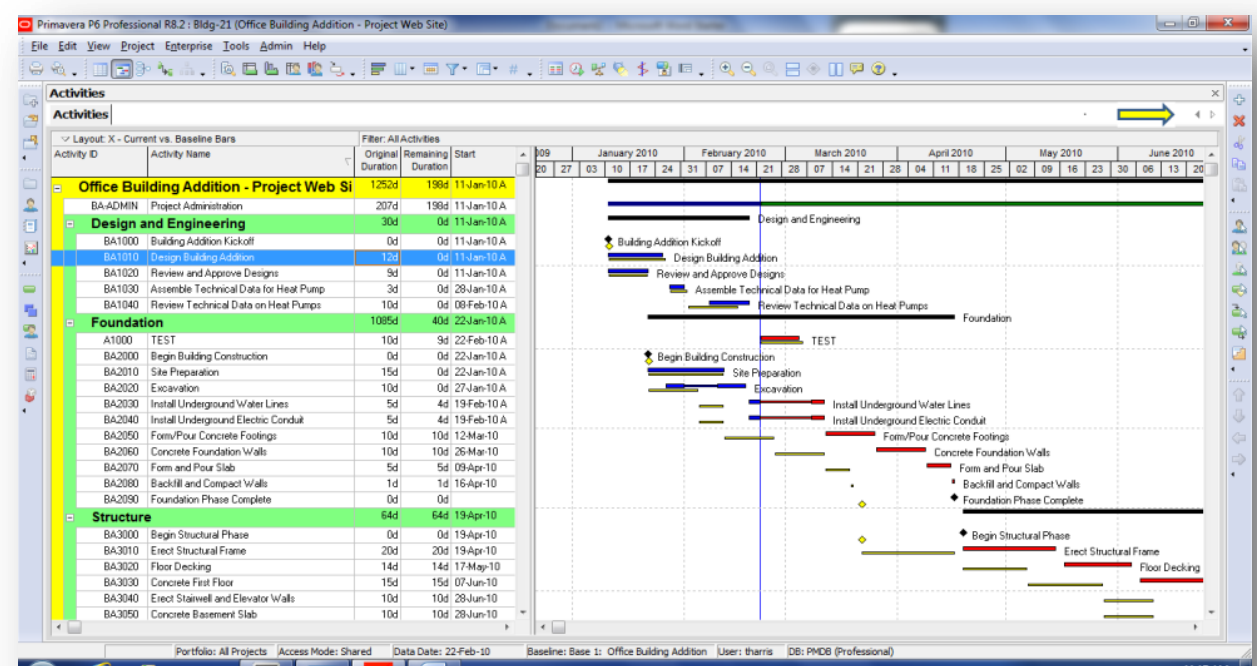

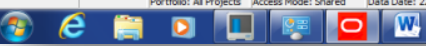

Fig-6 scheduling of a project by using Primavera 


\subsection{Work break down structure of a schedule project in primavera}

The WBS compels the venture supervisor, colleagues, and clients to portray the means required to construct and convey the item or administration. The activity alone empowers a discourse that will help clear up ambiguities, bring out presumptions, limit the extent of the venture, and raise basic issues right off the bat. It lays the preparation for building up a powerful timetable and great spending arranges. A very much characterized WBS empowers assets to be distributed to particular errands, helps in creating a significant timetable, and makes ascertaining a dependable spending plan simpler. The level of detail in a WBS makes it simpler to consider individuals responsible for finishing their assignments. With a characterized WBS, individuals can't stow away under the "front of broadness." An all around characterized errand can be allocated to a particular person, who is then in charge of its finish. The way toward creating and finishing a WBS breeds energy and responsibility. In spite of the fact that the venture chief will regularly build up the abnormal state WBS, he will look for the interest of his center group to substance out the outrageous detail of the WBS. This interest will start contribution in the venture. By using WBS the groundwork for developing an effective schedule and good budget plans. A well-defined WBS enabled resources to be allocated to specific tasks, helps in generating a meaningful schedule, and makes calculating a reliable budget easier. The process of developing and completing a WBS breeds excitement and commitment. Although the project manager will often develop the high-level WBS, he will seek the participation of his core team to flesh out the extreme detail of the WBS. This participation will spark involvement in the project as shown in the fig below The WBS compels the venture supervisor, colleagues, and clients to portray the means required to construct and convey the item or administration. The activity alone empowers a discourse that will help clear up ambiguities, bring out presumptions, limit the extent of the venture, and raise basic issues right off the bat. It lays the preparation for building up a powerful timetable and great spending arranges. A very much characterized WBS empowers assets to be distributed to particular errands, helps in creating a significant timetable, and makes ascertaining a dependable spending plan simpler

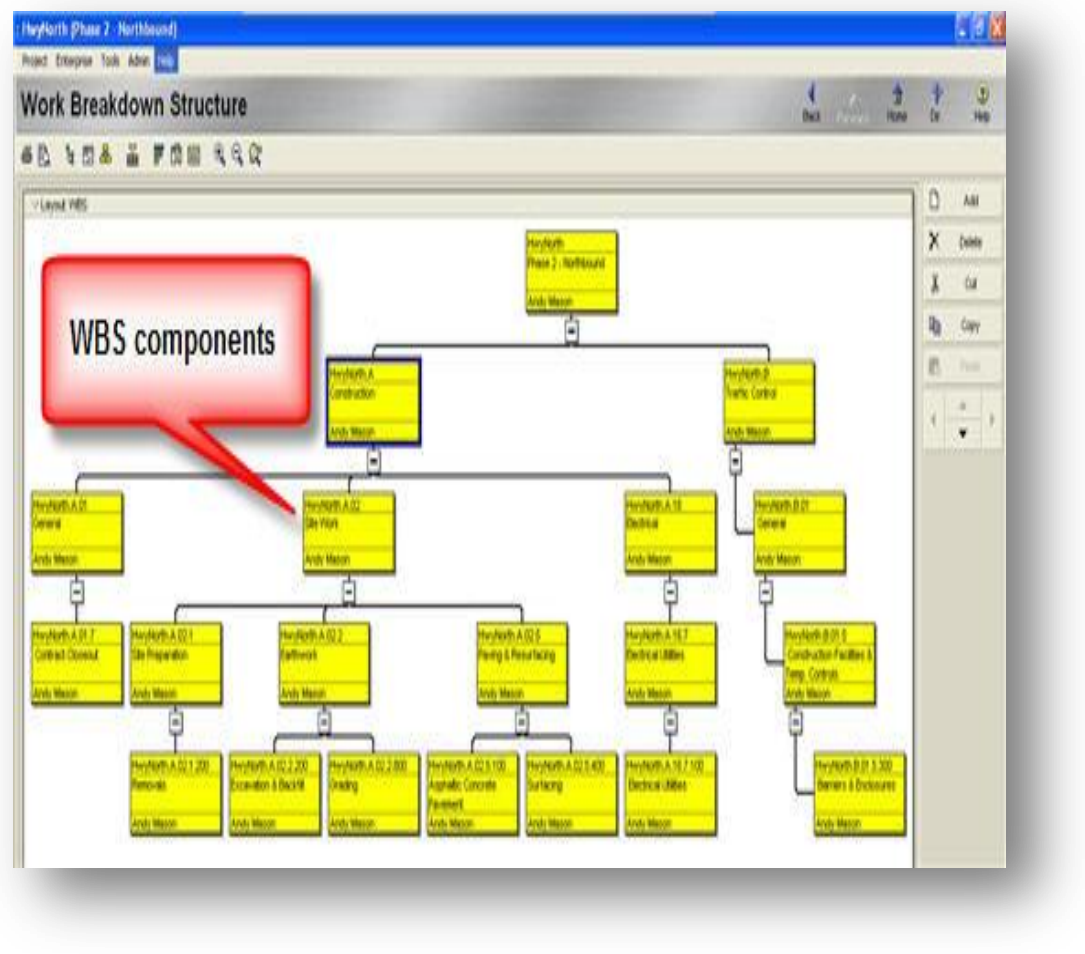

Fig -7 representing WBS components in Primavera

The WBS compels the venture supervisor, colleagues, and clients to portray the means required to construct and convey the item or administration. The activity alone empowers a discourse that will help clear up ambiguities, bring out presumptions, limit the extent of the venture, and raise basic issues right off the bat. It lays the preparation for building up a powerful timetable and great spending arranges. A very much characterized WBS empowers assets to be distributed to particular errands, helps in creating a significant timetable, and makes ascertaining a dependable spending plan simpler 


\subsection{Impact of 4D modeling on construction planning over traditional planning methods}

To decide the effect of 4D modeling, its advantages and inadequacies for the development arranging procedure are distinguished by exploring the literature review and writing. Likewise, the benefits of $4 \mathrm{D}$ arranging over customary arranging techniques and the difficulties in receiving 4D modeling strategies are likewise found.

\subsection{Benefits of 4D modeling}

There are many advantages of $4 \mathrm{D}$ modeling for development arranging recognized after looking into the contextual investigations which are dissected underneath.

\subsubsection{Better representation of development work}

A standout amongst the most critical advantages of $4 \mathrm{D}$ demonstrating is that it gives a superior representation of development work which is unrealistic to accomplish through 2D drawings and records, for example, Gantt graph and straight timetable. This empowers organizers to distinguish clashes and conflicts in the development stage amid the arranging handle

\subsubsection{More accurate work plan}

4D displaying permits extend group to create exact and far reaching work arrange which would be more hard to accomplish with conventional arranging strategies.. With the utilization of $4 \mathrm{D}$ modeling, the succession of the exercises in the work arrange and their effect on each other can be reenacted to check the legitimacy of the calendar and to upgrade the arranging procedure to use least assets in the development stage with greatest advantages and in least time. This prompts cost and time saving. While Gantt diagram can't present the relationship and the effect exercises have on each other. By utilizing the conventional strategies for arranging like Gantt graphs and CPM booking, it is not entirely obvious a few exercises in the development arrange because of absence of perception. While, 4D modeling give an extremely compelling apparatus to picture the building venture and distinguish all the conceivable development exercises prompting an exact and core work arrange. $4 \mathrm{D}$ modeling likewise help the organizers in designating assets

\subsubsection{Effective arranging}

Effective development arranging assumes a critical part in driving the venture to its victory. By inspecting the contextual analyses it is very conspicuous that $4 \mathrm{D}$ modeling empowers the organizers and venture groups to accomplish an exceptionally powerful and effective arranging of development works.

\subsubsection{Better correspondence}

4D model can be utilized as a successful specialized device between various venture partners. Contextual analysis 8 affirmed that 4D modeling assumed a critical part in correspondence amongst customer and organizers amid the arranging stage. 2D reports can prompt misconstruing between gatherings included on the grounds that they don't give a entire photo of the venture, yet, with 4D modeling, development performing artists can thoroughly comprehend the venture's points of interest significantly quicker; in this way a decent correspondence process can be set up.

\subsubsection{Planning of transitory structures and works}

Transitory works and structures assume a critical part in the execution of activities supporting the principle development handle. Conventional 2D arranging strategies like CPM booking and Gantt diagrams for the most part don't consider brief works and structures amid the arranging procedure which may bring about troubles at site amid execution. Be that as it may, 4D modeling empowers the organizer to arrange the impermanent works and structures also by fusing them into the model. As the displaying of brief structures including formwork, framework and tower cranes empowered a superior comprehension of development process and structures prompting a more compelling arranging.

\subsubsection{Exact amounts departure}

4D displaying empowers the organizer to quantify amounts all the more precisely and productively, which empowers a more viable arranging process. The 4D model likewise allows the organizer to decide the amounts of material required at a particular time of the venture, which brings about more exact arranging 


\section{Maximizing the efficiency of 4D modeling}

4D modeling is a gainful instrument for arranging process; however it should be more versatile to be perceived as one of the main arranging strategies. As saw in a large portion of the contextual analyses checked on, a noteworthy test confronted by the venture group was improvement of the 4D model. To address this issue, it is fitting to receive the model as right on time as conceivable in the venture. The model can be started from the idea stage of plan. The engineers must consider the extent of the model while its improvement that the model existence of the venture is long as it will be utilized till end of the venture for outline and 4D modeling. So the designers ought to guarantee that fundamental points of interest are incorporated into the model. This model in the wake of settling the feel of the building can be given over to the fashioners for help with the outline procedure. The originators can include more basic subtle elements into the model like sections, pillars and MEP detail. The way of venture ought to be remembered while advancing its model. A mind boggling venture requires a more definite model with consistently detail included. While, including an excessive number of points of interest in a less complex venture will be a misuse of exertion, time and assets. Once the plan of the building is finished, a similar 3D model can be utilized by the organizer to change into a 4D demonstrate. This will spare a great deal of time and facilitate the workload as the 3D perspectives of the model will be practically total and the organizer will simply need to chip away at building up the grouping and incorporating it with the model. The organizer can either utilize incorporated 4D BIM apparatuses or can interface the 3D demonstrate with the plan independently utilizing a 4D device for making the 4D display. The implicit booking interface in coordinated 4D BIM apparatus empowers connecting of physical items to the exercises inside the model. For a mind boggling venture with high probability of instabilities, an incorporated 4D BIM apparatus is suggested for the organizer as it permits ease in refreshing the model. Be that as it may, in a 4D instrument with interlinking of 3D model and the timetable

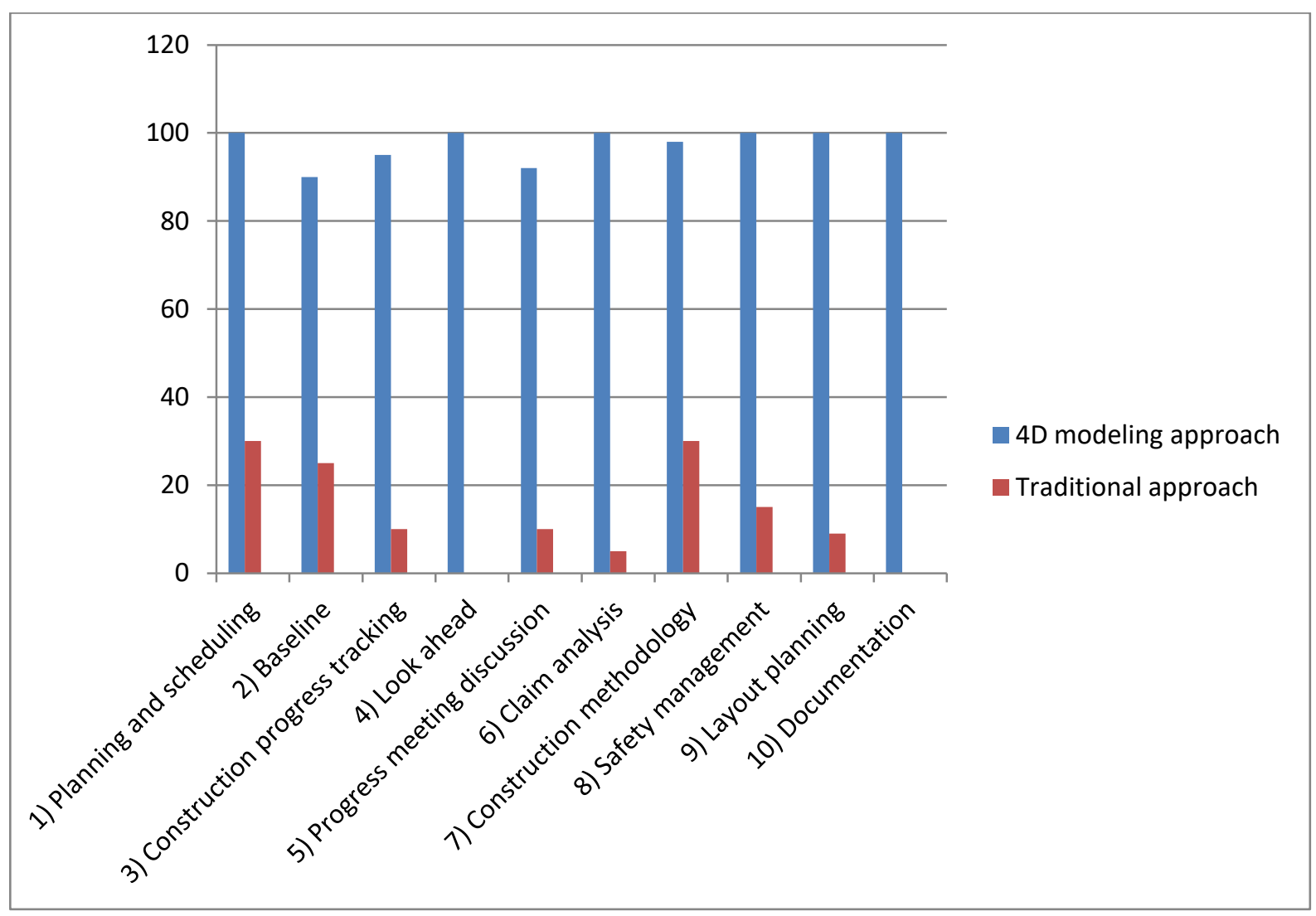




\section{Conclusion}

The research showed 4D modeling as a promising tool for construction planning. It gives us the positive impact and also the advantages that aren't able to achieve by the usage of the traditional methods of construction planning. The most foremost benefits of 4D modeling are found to be better visualization of construction work, easy communication between the different parties working on a project and helps in the increment of efficiency of the project. Implementation of 4D modeling helps in detection of errors and problems which could comes up after starting of the construction hence in the management of cost and time of the project, besides this 4D modeling helps in the detailed planning of the project and presents a comprehensive view of even small sections of the project. Therefore a more dependable and detailed work plan allows us to complete the project in assumed time and cost. Hence a detailed 3D view by revit and accurate construction planning by primavera sums up to be a promising 4D tools for planning of a project. By bringing in the above consideration 4D modeling should be extensively initiate in to the construction industry and could be adopt in alleviation of common problems to be come across in the project planning.

\section{Acknowledgement}

The successful completion of this project involves many people and we are extremely grateful to lecturers in civil engineering department for their excellent guidance right from selection of project and for encouragement throughout the completion of project.

We express our sincere thanks to our supervisor Ms. SUEBHA KHATOON, the main source for helping in selecting our project. She also suggested the suitable directions for our project. Her guidance showed the path towards the successful completion of project.

We express our sincere gratitude to Mr. Mohammed Safiuddin, Head of Civil Department for his encouragement during the progress of this project work.

We derive great pleasure in expressing our sincere gratitude to our Director R \& D Dr. Mohammed Masood bin Tayyab and Principal S ALTAF HUSSAIN, for their timely suggestions, which helped us to complete this project work successfully.

We thank both teaching and non teaching staff members of civil department for their kind cooperation and all sorts of help to complete our project work successfully.

\section{Journals Papers:}

\section{References}

[1]. Karlshøj, J. (2012). Not simply CAD ++. BIM Journal, Vol. 3: No. 28, pp. 39-42.

[2]. Kassem, M., Brogden, T., and Dawood, N. (2012). BIM and 4D arranging: an all encompassing investigation of the boundaries and drivers to far reaching reception. KICEM Journal of Construction Engineering and Project Management, Vol. 2: No. 4, pp: 1-10.

Books

[3]. Jung, Y., and Joo, M. (2011). Building Information Modeling (BIM) system for down to earth usage. Robotization in Construction, Vol. 20: No. 2, pp. 126-133

[4]. Khosrowshahi, F., and Arayici, Y. (2012). Guide for execution of BIM in the UK development industry. Designing, Construction and Architectural Management, Vol. 19: No. 6, pp. 610-635.

Theses

[5]. Keegan, C. J. (2010). Building data demonstrating in support of space arranging and redesign in schools and colleges. MSc Thesis, Construction Project Management, Faculty of Worcester Polytechnic Institute (WPI), U.S.A

About authors

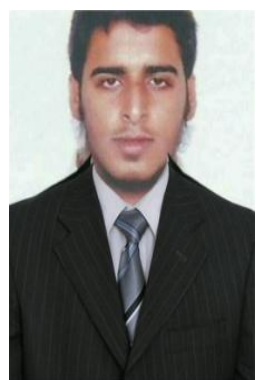

NEHAD ALI

KHAN

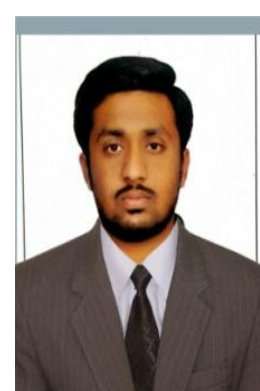

NIYAZ AHMED SHAREEF
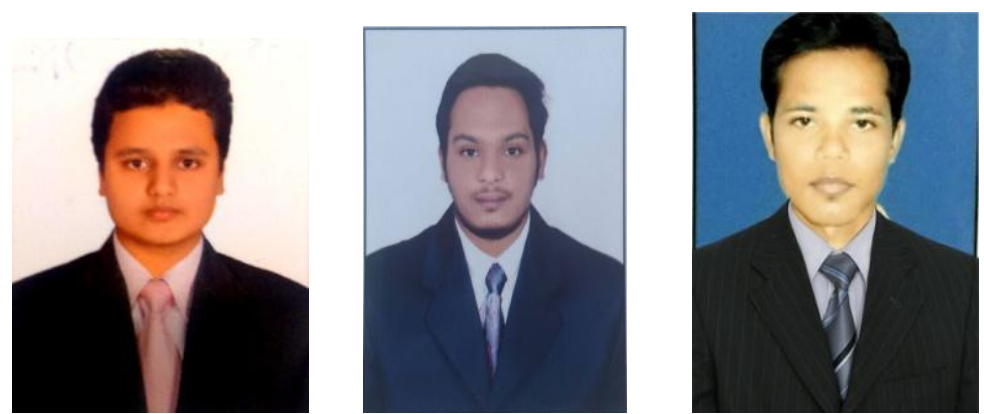

SYED NEMATH YHSANULLAH HYDER MOOSVI
UDDIN 